\title{
Dominant Negative Receptor
}

National Cancer Institute

\section{Source}

National Cancer Institute. Dominant Negative Receptor. NCI Thesaurus. Code C19360.

A receptor protein that inhibits the downstream functions of an associated receptor, which requires dimerization for activity. The dominant-negative receptor usually has an intact ligand binding region but is missing an intracellular enzymatic region. It may be a mutated form of a full length receptor or it may be in the same receptor family. 